\title{
Biomass, abundances, and abundance and geographical range size relationship of birds along a rainforest elevational gradient in Papua New Guinea
}

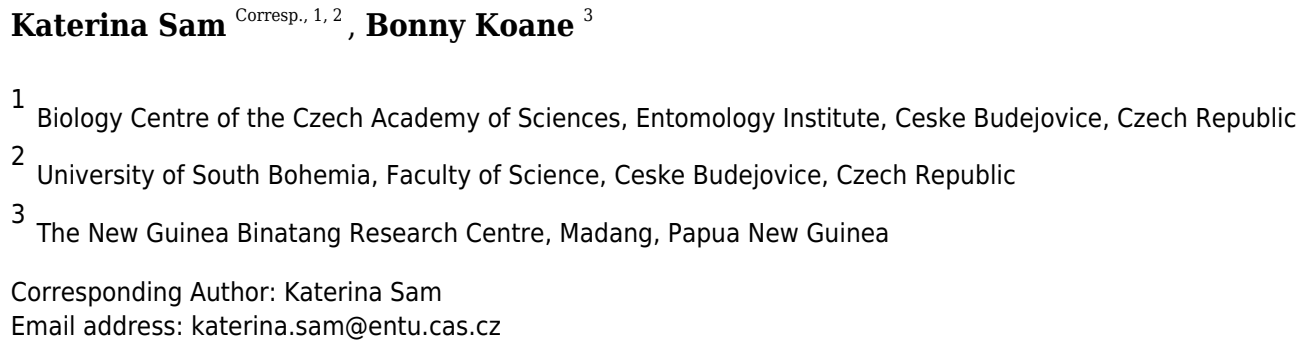

The usually positive inter-specific relationship between geographical range size and the abundance of local bird populations comes with exceptions. On continents, the majority of these exceptions have been described from tropical montane areas in Africa, where geographically-restricted bird species are unusually abundant. We asked how the local abundances of passerine and non-passerine bird species along an elevational gradient on Mt. Wilhelm, Papua New Guinea relate to their geographical range size. We collected data on bird assemblages at eight elevations ( 200 - 3,700 m, at 500 m elevational increments). We used a standardized point-counts at 16 points at each elevational study site. We partitioned the birds into feeding guilds, and we obtained data on geographical range sizes from Bird-Life International data zone. We observed a positive relationship between abundance and geographical range size in the lowlands. This trend changed to a negative one towards higher elevations. The total abundances of the assemblage showed a humpshaped pattern along the elevational gradient, with passerine birds, namely passerine insectivores, driving the observed pattern. In contrast to abundances, the mean biomass of the bird assemblages decreased with increasing elevation. Our results show that montane bird species maintain dense populations which compensate for the decreased available area near the top of the mountain. 


\section{Biomass, abundances, and abundance and}

\section{2 geographical range size relationship of birds along a}

\section{3 rainforest elevational gradient in Papua New Guinea}

4

5 Katerina Sam ${ }^{1,2}$, Bonny Koane ${ }^{3}$

6

$7{ }^{1}$ Biology Centre of the Czech Academy of Sciences, Entomology Institute, Ceske Budejovice,

8 Czech Republic

$9 \quad{ }^{2}$ University of South Bohemia, Faculty of Science, Ceske Budejovice, Czech Republic

12

Corresponding Author:

Katerina $\operatorname{Sam}^{1,2}$

Branisovska 31, 370 05, Ceske Budejovice, Czech Republic

Email address: Katerina.sam.cz@gmail.com

\begin{abstract}
The usually positive inter-specific relationship between geographical range size and the abundance of local bird populations comes with exceptions. On continents, the majority of these exceptions have been described from tropical montane areas in Africa, where geographically-restricted bird species are unusually abundant. We asked how the local abundances of passerine and nonpasserine bird species along an elevational gradient on Mt. Wilhelm, Papua New Guinea relate to their geographical range size. We collected data on bird assemblages at eight elevations (200 $3,700 \mathrm{~m}$, at $500 \mathrm{~m}$ elevational increments). We used a standardized point-counts at 16 points at each elevational study site. We partitioned the birds into feeding guilds, and we obtained data on geographical range sizes from Bird-Life International data zone. We observed a positive relationship between abundance and geographical range size in the lowlands. This trend changed
\end{abstract}


to a negative one towards higher elevations. The total abundances of the assemblage showed a hump-shaped pattern along the elevational gradient, with passerine birds, namely passerine insectivores, driving the observed pattern. In contrast to abundances, the mean biomass of the bird assemblages decreased with increasing elevation. Our results show that montane bird species maintain dense populations which compensate for the decreased available area near the top of the mountain.

\section{Introduction}

Many previous studies have found a positive inter-specific relationship between geographical range size and the abundance of local populations (Brown 1984; Gaston \& Blackburn 2000; Gaston et al. 2000). The authors hypothesized that (1) species utilizing a wider range or more abundant resources become more abundant and widely distributed (Brown 1984), (2) that high population growth leads to higher abundances and to more occupied sites or that (3) intensive dispersal produces a positive inter-specific abundance-range size relationship (Borregaard \& Rahbek 2010; Gaston et al. 2000). While there is extensive literature devoted to the patterns of species diversity along elevational gradients (McCain 2009; Rahbek 1995), these studies rarely combine species richness with the study of bird abundance and biomass, arguably more important parameters when it comes to the impact of birds on other trophic levels (but see e.g., (Romdal 2001; Terborgh 1977). Even fewer studies have combined these attributes of bird communities with an estimate of available resources (Ding et al. 2005; Ghosh-Harihar 2013; Price et al. 2014) and/or available area along mountain ranges (e.g., Ferenc et al. 2016; Price et al. 2014).

Furthermore, many studies do not address the potential differences between passerines and non-passerines or, they completely exclude non-passerine species. Klopfer \& MacArthur (1960) suggested that phylogenetically younger passerines should be relatively more abundant than nonpasserines in unstable environments. They assumed that younger passerines have a less limited central nervous capacity than non-passerines, making them more capable of fitting changing environmental stimuli. In this study, we aimed to test the analogous hypothesis that non-passerines will be more abundant in favorable tropical lowlands with stable climatic conditions than in the more variable environments at higher elevations. In the Himalayas, the ratio of passerines to nonpasserines increased very slowly between 160 and 2,600 $\mathrm{m}$ a.s.l., and abruptly between ca. 3,000 $-4,000 \mathrm{~m}$ a.s.1. (Price et al. 2014) (but note that not all non-passerines were surveyed). Similarly, passerine abundance increased relative to non-passerines with increasing elevation in the Andes (Terborgh 1977). Finally, bird studies focusing on the patterns of abundance or biomass in different feeding guilds along elevational gradients are rare, however, they are essential for improving our understanding of ecosystem dynamics and function.

Macroecological studies have often revealed positive interspecific correlations between geographical range sizes and the abundance of local populations (Brown 1984; Gaston \& Blackburn 2000; Gaston et al. 2000). The negative correlation between abundance and range-size was showed on temperate datasets (but see Blackburn et al. 2006) and in montane Africa, where the geographically restricted species are generally more abundant than species with large 
69

70

71

72

73

74

75

76

77

78

79

80

81

82

83

84

85

86

87

88

89

90

91

92

93

94

95

96

97

98

99

100

101

102

103

104

105

106

107

geographical ranges (Fjeldså et al. 2012, Ferenc et al. 2016, Reif et al. 2006). Several other recent studies of tropical montane taxa report that abundance is uncorrelated with (or negatively correlated to) geographical range size (Nana et al. 2014; Reeve et al. 2016) but see (Theuerkauf et al. 2017). The only existing study on this topic from Papua New Guinea showed that abundance was not related to range size (Freeman 2018). However, in contrast to other studies, this one was based solely on mist-netting data and range size was calculated as elevational breath instead of area (Freeman 2018).

The drivers behind the high abundances of montane forest species are unknown. However, several mutually non-exclusive hypotheses have been considered (Ferenc et al. 2016). These are: (1) Long-term climatic stability allows specialization of new ecological forms, which then leads to high local abundances of species at mountain tops (Fjeldså et al. 2012). (2) Species-poor communities compensate with increased density at high altitudes which then leads to high abundances of montane bird species (MacArthur 1972). (3) Locally abundant tropical montane species have a higher chance of surviving despite their small range sizes while insufficiently abundant species go extinct (Johnson 1998).

To investigate the relationship between abundance and area in different regions, we focused on bird assemblages along the elevational gradient of Mt. Wilhelm in Papua New Guinea. Our goals were to investigate (1) the trends in abundances of birds along the elevational gradient, (2) the changes in relative abundances of different groups of birds (passerines and non-passerines, various feeding guilds), and (3) the effects of geographical range sizes on the abundance of individual species.

\section{Materials \& Methods}

The study was performed along Mt Wilhelm (4,509 m a.s.1.) in the Central Range of Papua New Guinea (Figure 1a, b). The complete rainforest gradient spanned from the lowland floodplains of the Ramu river (200 $\mathrm{m}$ a.s.1., $\left.5^{\circ} 44^{\prime} \mathrm{S} 145^{\circ} 20^{\prime} \mathrm{E}\right)$ to the treeline $\left(3700 \mathrm{~m}\right.$ a.s.1., $5^{\circ} 47^{\prime} \mathrm{S} 145^{\circ} 03^{\prime} \mathrm{E}$; Fig. 1). We completed the study along a $30 \mathrm{~km}$ long transect, where eight sites were evenly spaced at $500 \mathrm{~m}$ elevational increments. Because of the steep terrain, elevation could deviate by $50 \mathrm{~m}$ within each study site. Survey tracks and study sites at each elevation were directed through representative and diverse microhabitats (e.g., ridges, valleys, rivulets; $\geq 250 \mathrm{~m}$ from forest edge). In the lowlands, average annual precipitation is $3,288 \mathrm{~mm}$, rising to $4,400 \mathrm{~mm}$ at $3,700 \mathrm{~m}$ a.s.l. There is a distinct condensation zone at around 2,500 - 2,700 $\mathrm{m}$ a.s.l. (McAlpine et al. 1983). Mean annual temperature typically decreases at a constant rate of $0.54^{\circ} \mathrm{C}$ per 100 elevational meters; from $27.4^{\circ} \mathrm{C}$ at the lowland site $\left(200 \mathrm{~m}\right.$ a.s.1.) to $8.37^{\circ} \mathrm{C}$ at the tree line $(3700 \mathrm{~m}$ a.s.1.). The habitats of the elevational gradient is described as lowland alluvial forest (200 $\mathrm{m}$ a.s.l.), foothill forest (700 and 1,200 $\mathrm{m}$ a.s.1.), lower montane forest (1,700 - 2,700 $\mathrm{m}$ a.s.1.), and upper montane forest (3,200 and 3,700 m a.s.l.; according to Paijmans (1976). Plant species composition of the forest (Paijmans 1976), general climatic conditions (McAlpine et al. 1983) and habitats at individual study sites (Sam \& Koane 2014) are described elsewhere. 
108

109

110

111

112

113

114

115

116

117

118

119

120

121

122

123

124

125

126

127

128

129

130

131

132

133

134

135

136

137

138

139

140

141

142

143

144

145

146

147

Data on bird communities were collected in 2010, 2011 and 2012 during the wet and dry seasons, using a standardized point-counts at 16 points per elevation (Sam \& Koane 2014; Sam et al. 2019). Both visual observations and identifications based on calls were used. The surveys were conducted in the mornings between 0545 and 1100 . Each of the 16 sample points had a radius of $50 \mathrm{~m}$ (area 0.785 ha per point, which makes 12.56 ha per elevational study site). Points were located $150 \mathrm{~m}$ apart to lower the risk of multiple encounters of the same individuals. We visited each point 14 times ( 8 times during the dry season and 6 times during the wet season). The order of the points was altered during each re-survey, to avoid biases due to time of day. Birds were detected for 15 minutes during each visit at each point. This resulted in 240 minutes of daily surveys. During the point-counts, we used a distance sampling protocol. The birds were recorded in five 10-m-wide radial distance bands (Buckland et al. 2001). Detection adjustments, however, proved to come with significant problems in the tropics (Banks-Leite et al. 2014). Therefore, we used the observed abundance only estimates instead of the distance sampling-based estimates in the analyses (see similar reasons and discussion by Ferenc et al. 2016). To evaluate the consistency in our data, we (1) compared the abundances of birds observed during point-counts (reported here) and from mist-netting conducted at the same sites during the same surveys (Sam et al. 2019), (2) we ran all the analyses reported here also with mist-netting data, and we (3) we compared the abundances of the birds recorded during point-counts done in wet and dry season (Figure S1-S3). The data showed that abundances obtained by mist-netting and by point-counts and by pointcounts in wet and dry season are well correlated, and that the trends remain unchanged, when only mist-netting data are used (Figure S1-S3).

We recorded the number of individuals of each species at any of the 15-min intervals and summed them across all 16 points of each survey day at the certain elevation. Then we averaged these daily abundances across the 14 days (or 6 days of wet season and 8 days of dry season respectively at each elevation). Hereafter we call this measure "mean elevational abundance" of a given species at a certain elevational site. After that, we averaged the mean elevational abundance across the elevations where the bird species was present to calculate "mean abundance" of a given species along the elevational gradient. Species at their elevational range limits usually have low abundances which might be difficult to detect correctly. Therefore, potential errors, which would lead to an erroneous mean abundance, might occur if rare individuals at the sites close to their range limits are missed during census. To ensure that our observations are valid, we also repeated the analyses with the "maximal mean elevational abundance" of each species (Figure S4).

To summarize the abundances of bird assemblages at a given elevation (hereafter "total abundance") we calculated the sum of the mean elevational abundance of all species present at each site (i.e. at 16 points within a 4-hour long survey). Elevations between minimal and maximal range where birds were missing were not considered, i.e., data were not extrapolated, and the birds were given zero abundance at this elevation. The taxonomy used followed the International Ornithological Congress World Bird List version 6.1.

The elevational weighted mean point was calculated as the elevation, where the species had potentially the highest abundances. Weighted mean point was calculated as a sum of elevations 
148 weighed by an abundance of the given species at this elevation which was divided by the sum of 149 the abundances (e.g. Elevation $1 *$ abundance at elevation $1+$ elevation $2 *$ abundance at elevation 150 2)/(abundance at elevation $1+$ abundance at elevation 2) (Figure S4). Based on the weighted mean 151 point, we divided the species into three groups as follows: (a) "lowland" group - species with their 152 elevational weighted mean point in the lower part of the elevational gradient (up to $800 \mathrm{~m}$ a.s.l.), 153 (b) "middle" group - species with a weighted mean point between 800 and $1600 \mathrm{~m}$ a.s.l., and (c) 154 "montane" group - species with their weighted mean point in the upper third of the gradient (above 155 1,600 $\mathrm{m}$ a.s.l.). Note that a single species (Great cuckoo-dove - Reinwardtoena reinwardti), 156 occurring at all sites along the complete gradient between 200 and 3,200 m, thus falls into the

157

158

159

160

161

162

163

164

165

166

167

168

169

170

171

172

173

174

175

176

177

178

179

180

181

182

183

184

185

186

187

group of montane species. To confirm the validity of our data, we also repeated our analyses with the maximal mean elevational abundance point, i.e. the elevational site where we recorded the maximal mean elevational abundance (Figure S4).

All recorded bird species were classified into five trophic guilds: insectivores, frugivores, frugivores-insectivores, insectivores-nectarivores and nectarivores based on dietary information from standard references (Hoyo et al. 1992-2011; Pratt \& Beehler 2015) and our data (Sam et al. 2019; Sam et al. 2017). Abundances of passerines and non-passerines and individual feeding guilds were compared by non-parametric Kruskal-Wallis tests. We report the mean $\pm \mathrm{SE}$ and abundances per 12.56 ha recorded in a 15-minute-long census unless we state otherwise. Geographical range sizes of all birds were obtained from Bird-Life International data zone web pages accessed in July 2016. Bodyweight (mean for males) of the birds were obtained from Hoyo et al. (1992-2011). Bird metabolism was calculated from bodyweight according to available equations (McNab 2009).

We conducted the field work under the Institutional Animal Care and Use Committee approval permit No. 11800056119 and 99902077829 awarded by the PNG National Research Institute permit. Research was also permitted by Australian Bird and Bat Banding permit No. 3173. The data were collected at the land of several rainforest dwelling communities. The customary landowners (Peter Sai, Family Mundo, Alois Koane, Simon Yamah, Samson Yamah, Joe Black) gave fully informed verbal and prior consent to the study of bird communities on their land along Mt. Wilhelm gradient. The negotiations with landowners were organized via The New Guinea Binatang Research Centre, an NGO in Papua New Guinea.

\section{Results}

In total, we recorded 25,715 birds belonging to 249 (Table S1) species from the point-counts along the elevational gradient of Mt. Wilhelm. This represents $87 \%$ of bird species recorded along the gradient so far (Marki et al. 2016; Sam \& Koane 2014; Sam et al. 2019). Total bird species richness seemed to show a plateau at lower elevations (up to $1700 \mathrm{~m}$ a.s.1.) and decreased with increasing elevation afterward (Figure 2a). In contrast, total abundance of birds showed a humped shaped pattern, peaking between 1,700 and 2,700 m a.s.l. with ca. 420-450 individuals of all birds per 16 sampling points (i.e., $12.86 \mathrm{ha}$ ) (Figure 2c).

\section{Passerines and non-passerines}

Peerj reviewing PDF | (2019:07:39040:2:1:CHECK 1 Jul 2020) 
188 Passerines were overall more species rich along the elevational gradient, represented by 161

189

190

191

192

193

194

195

196

197

198

199

200

201

202

203

204

205

206

207

208

209

210

211

212

213

214

215

216

217

218

219

220

221

222

223

224

225

226

227

species in comparison to non-passerines represented by 88 species (Figure $2 \mathrm{~b}$ ). We observed a linearly decreasing pattern in species richness of non-passerine birds $(\mathrm{N}=8, \mathrm{y}=-5.9167 \mathrm{x}+$ $\left.60.056, \mathrm{R}^{2}=0.96\right)$ along the elevational gradient and a hump-shaped pattern $\left(\mathrm{N}=8, \mathrm{y}=-2.1012 \mathrm{x}^{2}\right.$ $\left.+18.982 \mathrm{x}+27.315, \mathrm{R}^{2}=0.92\right)$ in species richness of passerine birds (Figure $2 \mathrm{~b}$ ). The species richness of passerines $(\mathrm{r}=0.52, \mathrm{P}=0.19, \mathrm{~N}=8)$ and non-passerines $(\mathrm{r}=0.91, \mathrm{P}=0.001, \mathrm{~N}=8)$ correlated with their total abundance (Figure 2b, c).

The mean elevational abundance of passerine birds was overall significantly higher (mean $\pm \mathrm{SD}=3.90 \pm 4.8$ ) than the mean elevational abundance of non-passerines (mean $\pm \mathrm{SD}=2.46 \pm$ $3.1 ; \mathrm{W}=21438 ; \mathrm{P}<0.001)$. The mean elevational abundance of assemblages increased with increasing elevation, with approximately 2.5 times as many individuals per non-passerine species and nearly twice as many individuals per passerine species at the highest elevation than in the lowlands (Figure 3). The pattern was similar in both wet and dry seasons (Figure S5). This pattern remains to be valid even when only the maximal mean elevational abundance were considered. Birds having their maximal mean elevational abundance at higher elevations had abundances higher than birds with maxima in lowlands (Figure S6)

Passerine birds with an elevational weighted mean point in the montane forest (above 1600 $\mathrm{m}$ a.sl.) had a higher mean abundance than those with a middle and lowland distribution (Figure 4a, Table S1). However, with their increasing elevational weighted mean point, the geographical ranges of the species decreased (Figure 4b). We found no significant change in the mean elevational abundance of non-passerine birds with an elevational weighted mean point (Figure 4c) but similarly to passerines, non-passerines with a higher elevational weighted mean point had smaller ranges (Figure 4c). The abundance range-size relationships for all bird species of the complete forestal gradient of Mt. Wilhelm showed a significantly negative relationship $\left(\mathrm{F}_{1,248}=\right.$ 8.22, $\mathrm{P}=0.004$, Figure S7). The trends remained negative, albeit nonsignificant, for passerines $\left(\mathrm{F}_{1,159}=1.17, \mathrm{P}=0.28\right)$ and non-passerines $\left(\mathrm{F}_{1,86}=2.6, \mathrm{P}=0.10\right)$ separately (Figure $\left.\mathrm{S} 7\right)$. However, the relationship of the three bird groups with different elevational weighted mean points showed a variable pattern, as the trend changed from a positive relationship in the lowland group of species, to no trend for middle species, and a negative trend for montane species (Figure S8). The pattern remained similar, when we split the data into abundances in the wet and dry season (Figure S9). Furthermore, the pattern remains unchanged even when the maximal mean elevational abundance is considered in analyses, as the maximal mean elevational abundance point and weighted mean point correlated closely (Figure S10). Finally, more abundant passerine montane birds had not only larger geographical ranges, but also longer elevational ranges (Figure S11).

\section{Feeding guilds}

Without respect to which feeding guild they belong, species occurring at low elevations usually had a lower mean elevational abundance than species occurring at high elevations (Figure 4a) i.e., their mean elevational abundance increased with increasing elevation. Nectarivorous and insectivore-nectarivorous species had the highest mean elevational abundance which increased

PeerJ reviewing PDF | (2019:07:39040:2:1:CHECK 1 Jul 2020) 
228

229

230

231

232

233

234

235

236

237

238

239

240

241

242

243

244

245

246

247

248

249

250

251

252

253

254

255

256

257

258

259

260

261

262

263

264

265

266

267

towards higher elevations (Figure 5a). Within insectivore-nectarivores, the pattern was driven purely by the presence of flocks of nectar-feedings lorikeets at high elevations (i.e. the pattern disappeared when we removed lorikeets from the dataset).

Total abundances of bird assemblages belonging to different feeding guilds however showed different patterns (Figure 5b). While total abundances of insectivores followed a midelevational peak (Figure 5b), total abundances of other feeding guilds showed no trend (Figure $5 b)$.

Within passerine birds, the mean elevational abundance of birds belonging to different feeding guilds (except frugivores) increased with their elevational weighted mean point (Figure 5c). In contrast, the mean elevational abundance of non-passerines birds belonging to various feeding guilds showed various patterns (Figure $5 \mathrm{~d}$ ).

Mean biomass of bird communities (Figure 6) recorded at each elevational study site decreased with increasing elevation, thus showing a different pattern from mean elevational abundance and total abundance. At the two highest elevations (3,200 and 3,700 m) mean biomass of passerines was relatively larger than biomass of non-passerines. The pattern of decreasing biomass was observed both with passerines and non-passerines (Figure 6a), as well as in all feeding guilds (Figure 6b). Because large species may have larger ranges (Gaston 1996), we tested how strong the relationship was between body size and geographical range. We found a weakly positive correlation between body size and range size in non-passerines, and no correlation in passerine birds (Figure S12).

\section{Discussion}

In this study we focused on the patterns and relationships in species richness, abundance and range size in assemblages of passerine and non-passerine birds along a tropical, elevational gradient. After a detectable, initial plateau at low elevations, overall species richness declined with increasing elevation on Mt. Wilhelm (Sam et al. 2019), a pattern that is typical for mountains with a humid base (McCain 2009). Further, when considered separately the species richness patterns of passerines (hump-shaped) and non-passerines (steeply decreasing) differed. The findings are, in part, similar to those from Himalaya (Price et al. 2014), where species richness of non-passerines decreased with increasing elevation but passerines followed a hump-shaped pattern and their richness peaked at ca. $2000 \mathrm{~m}$.

Total abundance of bird assemblages at individual elevations also follows a different hump-shaped pattern. This mismatch in patterns between observed species richness and abundance is an interesting observation. Previous studies show that unimodal or linearly decreasing patterns in density are usually paralleled by the patterns of total species richness along the same gradients (e.g., Romdal 2001; Terborgh 1977). Our findings are similar to patterns in abundances of birds observed along an elevational gradient in Cameroon (Ferenc et al. 2016). In this study, declining species richness was associated with minimal changes in the total abundance (i.e. the number of individuals per species) of birds because the average number of individuals per species increased with increasing elevation. 
268

269

270

271

272

273

274

275

276

277

278

279

280

281

282

283

284

285

286

287

288

289

290

291

292

293

294

295

296

297

298

299

300

301

302

303

304

305

306

307

Overall, the trends exhibited by total abundance and species richness do not correspond to one another. However, when total abundance is partitioned into the hump-shaped trend for passerines and decreasing trend for non-passerine birds, the trends become complementary with their respective species richness. To our knowledge, there is not a single study focusing separately on the abundance patterns of passerine and non-passerine birds along an elevational gradient. Our data further show that the species richness and abundance of passerines increase relative to nonpasserines with increasing elevation. This might be in concordance with previous suggestions that phylogenetically younger passerines should be relatively more abundant in less favorable and unstable environments. Klopfer \& MacArthur (1960) showed that the proportions of nonpasserines to passerines changes from north to south. A study comparable to ours by Price et al. (2014) indicated that the ratio between the abundances of passerines and non-passerines increased very slowly between 160 and 2,600 m a.s.1., and then increased abruptly between ca. 3,000 - 4,000 m a.s.1..

The widespread pattern that abundance is positively correlated with geographic range size (Gaston \& Blackburn 2000) does not seem to apply to New Guinean birds distributed along elevational gradients. Contrary to this widely accepted pattern, we described a negative correlation between the local abundance of birds and the complete range size of the given species. The deviation from a positive abundance-area relationship is caused by the combination of the decreasing range size and increasing abundance of birds towards high elevations. This observation is also consistent with the idea of taxon cycles whereby endemic species are confined to mountain tops. This observation also fits the predictions of the density compensation hypothesis in which individual species may increase their abundances to fill the available ecological space in speciespoor assemblages (MacArthur et al. 1972). The hypothesis thus assumes that small-range species that have insufficiently sparse local populations become extinct.

We showed that New Guinean bird species with small ranges are associated with high local abundances, as has been suggested for marsupials in Australia (Johnson 1998), birds of the Australian wet tropics (Williams et al. 2009) and Afromontane birds (Ferenc et al. 2016). There are only a few previous examples of datasets that report either nonsignificant or negative abundance-range-size relationships from birds in temperate zones (Gaston 1996; Päivinen et al. 2005). However, several studies have reported nonsignificant or negative abundance-range-size relationships from the birds in the tropics (Ferenc et al. 2016; Nana et al. 2014; Reeve et al. 2016; Reif et al. 2006). Although, studies reporting a positive trend (Theuerkauf et al. 2017) or no trend (Freeman 2018) in the tropics also exist.

The species richness of birds declined (with a lowland plateau) with increasing elevation on Mt Wilhelm (Sam et al. 2019). This is a typical pattern for mountains with a humid base (McCain 2009). However, we found that the number of individuals per bird species increased with increasing elevation and decreasing area. Further investigations of our data and its partitioning into feeding guilds showed that patterns of abundances for passerine birds are driven by insectivorous birds, while frugivores drive the decreasing pattern in non-passerines. This, in turn, is driven solely by the species richness of the feeding guild within the two groups of birds. A high proportion of 
308 the non-passerine birds of Mt. Wilhelm are identified as frugivorous (44\%) and insectivorous

309

310

311

312

313

314

315

316

317

318

319

320

321

322

323

324

325

326

327

328

329

330

331

332

333

334

335

336

337

338

339

340

341

342

343

344

345

346

347

(29\%), whereas, most of the passerines (59\%) are insectivorous.

The contrasting pattern for the total abundance of passerine and non-passerine bird assemblages is an interesting observation considering the decreasing trend in overall environmental productivity (McCain 2009) and food availability (estimated by the abundance of insects and fruits) along the elevational gradient (e.g., Janzen et al. 1976; Loiselle \& Blake 1991), especially along wet mountains like Mt. Wilhelm (McCain 2009). Along Mt. Wilhelm, abundances of arthropods followed a humped-shaped pattern with a peak at ca. $1700 \mathrm{~m}$ (Sam et al. 2020, Supriya et al. 2019, Volf et al. 2020), providing the best food resources for insectivorous passerines in the middle of the gradient. In contrast, abundance as well as biomass of fruits decreased steeply with increasing elevation (Hazel 2019, Segar et al. 2013). Considering that $71 \%$ of non-passerines feed on fruits and/or nectar while at least $68 \%$ of passerines feed solely on insects, the observed patterns in total abundance might be shaped by the availability of resources. Additionally, abundance patterns in both groups of birds are parallel to the species richness of these groups along our gradient. This corresponds to previously reported results on the relationships between abundance and species richness along elevational gradients (Terborgh 1977).

Mean biomass of bird communities recorded at each elevational study site decreased quite steeply with increasing elevation, showing a different pattern than the total abundance of birds at given sites. At the upper most two elevations (3,200 and 3,700 m) mean biomass of passerines was relatively larger than biomass of non-passerines which corresponds, in part, with their mean elevational abundance at these elevations. The decrease in bird biomass suggests a decrease in energy flux at given elevations, very likely because of reduction of primary productivity (Dolton $\&$ de L. Brooke 1999).

\section{Conclusions}

In direct contrast to the abundance-geographical range size relationship hypothesis investigated here, we found that montane species which associated with small geographical ranges have locally higher abundances than lowland species which are associated with large geographical ranges. The mean abundances of passerine and non-passerine birds follow a similar trend (significant for passerines, but nonsignificant for non-passerines), with montane birds having higher abundances then lowland birds. Abundances of passerines seem to be driven by insectivores, while nonpasserines seem to be driven by frugivores. Our data further show that passerines and nonpasserines have different patterns of species richness and total abundance along the same elevational gradient.

\section{Acknowledgments}

We wish to thank numerous field assistants from Kausi, Numba, Bundi, Bruno Sawmill, Sinopass, and Kegesugl for help in the field and hospitality.

\section{References}


348

349

350

351

352

353

354

355

356

357

358

359

360

361

362

363

364

365

366

367

368

369

370

371

372

373

374

375

376

377

378

379

380

381

382

383

384

385

386

387

388

389

390

391

392

393

394

395

396

Banks-Leite C, Pardini R, Boscolo D, Cassano CR, Püttker T, Barros CS, and Barlow J. 2014. Assessing the utility of statistical adjustments for imperfect detection in tropical conservation science. Journal of Applied Ecology 51:849-859.

Blackburn TM, Cassey P, and Gaston KJ. 2006. Variations on a theme: sources of heterogeneity in the form of the interspecific relationship between abundance and distribution. Journal of Animal Ecology 75:1426-1439.

Borregaard MK, and Rahbek C. 2010. Causality of the relationship between geographic distribution and species abundance. The quarterly review of biology 85:3-25.

Brown JH. 1984. On the relationship between abundance and distribution of species. The American Naturalist 124:255-279.

Buckland S, Anderson D, Burnham K, Laake J, Borchers D, and Thomas L. 2001. Introduction to distance sampling: Oxford University Press. Oxford Considerations and Management Recommendations: Wildlife Society Bulletin 34:1393-1395.

Ding TS, Yuan HW, Geng S, Lin YS, and Lee PF. 2005. Energy flux, body size and density in relation to bird species richness along an elevational gradient in Taiwan. Global Ecology and Biogeography 14:299-306.

Ferenc M, Fjeldså J, Sedláček O, Motombi FN, Nana ED, Mudrová K, and Hořák D. 2016. Abundancearea relationships in bird assemblages along an Afrotropical elevational gradient: space limitation in montane forest selects for higher population densities. Oecologia 181:225-233.

Fjeldså J, Bowie RC, and Rahbek C. 2012. The role of mountain ranges in the diversification of birds. Annual Review of Ecology, Evolution, and Systematics 43:249-265.

Freeman BG. 2018. No evidence for a positive correlation between abundance and range size in birds along a New Guinean elevational gradient. Emu-Austral Ornithology:1-9.

Gaston KJ. 1996. The multiple forms of the interspecific abundance-distribution relationship. Oikos:211220.

Gaston KJ. 1996. Species-range-size distributions: patterns, mechanisms and implications. Trends in Ecology \& Evolution. 11:197-201.

Gaston KJ, and Blackburn TM. 2000. Pattern and Process in Macroecology. Oxford: Blackwell Publishing.

Gaston KJ, Blackburn TM, Greenwood JJ, Gregory RD, Quinn RM, and Lawton JH. 2000. Abundanceoccupancy relationships. Journal of Applied Ecology 37:39-59.

Ghosh-Harihar MJ. 2013. Distribution and abundance of foliage-arthropods across elevational gradients in the east and west Himalayas. Journal of animal ecology 28:125-130.

Hazel RJ. 2019. Functional alpha- and beta-diversity of birds and fruits on an elevational gradient in Papua New Guinea. PhD thesis. University of Sussex.

Hoyo dJ, Elliott J, Sargatal J, and Christie DA. 1992-2011. Handbook of the Birds of the World (vol. 116). Barcelona, Spain: Lynx Editions.

Janzen DH, Ataroff M, Fariñas M, Reyes S, Rincon N, Soler A, Soriano P, and Vera M. 1976. Changes in the arthropod community along an elevational transect in the Venezuelan Andes. Biotropica 8:193-203.

Johnson C. 1998. Species extinction and the relationship between distribution and abundance. Nature 394:272-274.

Klopfer PH, and MacArthur RH. 1960. Niche size and faunal diversity. American Naturalist :293-300.

Loiselle BA, and Blake JG. 1991. Temporal variation in birds and fruits along an elevational gradient in Costa Rica. Ecology:180-193.

MacArthur RH. 1972. Geographical ecology: patterns in the distribution of species: Princeton University Press.

MacArthur RH, Diamond JM, and Karr JR. 1972. Density compensation in island faunas. Ecology 53:330-342.

PeerJ reviewing PDF | (2019:07:39040:2:1:CHECK 1 Jul 2020) 
397

398

399

400

401

402

403

404

405

406

407

408

409

410

411

412

413

414

415

416

417

418

419

420

421

422

423

424

425

426

427

428

429

430

431

432

433

434

435

436

437

438

439

440

441

442

443

444

445

446

447

Marki PZ, Sam K, Koane B, Kristensen JB, Kennedy JD, and Jønsson KA. 2016. New and noteworthy bird records from the Mt. Wilhelm elevational gradient, Papua New Guinea. Bulletin of Brittish Ornithology Club 137:263-271.

McAlpine JR, Keig R, and Falls R. 1983. Climate of Papua New Guinea. CSIRO and Australian National University Press, Canberra.

McCain CM. 2009. Global analysis of bird elevational diversity. Global Ecology and Biogeography 18:346-360.

Nana ED, Sedláček O, Bayly N, Ferenc M, Albrecht T, Reif J, Motombi FN, and Hořák D. 2014. Comparison of avian assemblage structures in two upper montane forests of the Cameroon volcanic line: lessons for bird conservation. Biodiversity and Conservation 23:1469-1484.

Paijmans K. 1976. New Guinea Vegetation. In: Paijmans K, editor. Canberra: National University Press. p $212 \mathrm{pp}$.

Päivinen J, Grapputo A, Kaitala V, Komonen A, Kotiaho JS, Saarinen K, and Wahlberg N. 2005. Negative density-distribution relationship in butterflies. Bmc Biology 3:5.

Pratt TK, and Beehler BM. 2015. Birds of New Guinea: Princeton University Press.

Price TD, Hooper DM, Buchanan CD, Johansson US, Tietze DT, Alström P, Olsson U, Ghosh-Harihar M, Ishtiaq F, and Gupta SK. 2014. Niche filling slows the diversification of Himalayan songbirds. Nature 509:222-225.

Rahbek C. 1995. The elevational gradient of species richness: a uniform pattern? Ecography 18:200-205.

Reeve AH, Borregaard MK, and Fjeldså J. 2016. Negative range size-abundance relationships in Indo-Pacific bird communities. Ecography 39:990-997.

Reif J, Hořák D, Sedláček O, Riegert J, Pešata M, Hrázský Z, Janeček Š, and Storch D. 2006. Unusual abundance-range size relationship in an Afromontane bird community: the effect of geographical isolation? Journal of Biogeography 33:1959-1968.

Romdal TS. 2001. Altitudinal distribution and abundance patterns of bird species in the Eastern Arc Mountains, Tanzania. Scopus 21:35-54.

Sam K, and Koane B. 2014. New avian records along the elevational gradient of Mt. Wilhelm, Papua New Guinea. Bulletin of the British Ornithologists' Club 134:116-133.

Sam K, Koane B, Bardos DC, Jeppy S, and Novotny V. 2019. Species richness of birds along a complete rain forest elevational gradient in the tropics: Habitat complexity and food resources matter. Journal of Biogeography 46:279-290.

Sam K, Koane B, Jeppy S, Sykorova J, and Novotny V. 2017. Diet of land birds along an elevational gradient in Papua New Guinea. Scientific Reports 7:44018.

Sam K, Koane B, Sam L, Mrazova A, Segar S, Volf M, Moos M, Simek P, Sisol M, and Novotny V. 2020. Insect herbivory and herbivores of Ficus species along a rain forest elevational gradient in Papua New Guinea. Biotropica. 52:263-276.

Segar ST, Volf M, Zima Jnr J, Isua B, Sisol M, Sam L, Sam K, Souto-Vilarós D, and Novotny V. 2017. Speciation in a keystone plant genus is driven by elevation: a case study in New Guinean Ficus. Journal of Evolutionary Biology. 30:512-523.

Supriya K, Moreau CS, Sam K, and Price TD. 2019. Analysis of tropical and temperate elevational gradients in arthropod abundance. Frontiers of Biogeography, 11:e4310.

Terborgh J. 1977. Bird species diversity on an Andean elevational gradient. Ecology 58:1007-1019.

Theuerkauf J, Chartendrault V, Desmoulins F, Barré N, and Gula R. 2017. Positive range-abundance relationships in Indo-Pacific bird communities. Journal of Biogeography 44:2161-2163.

Volf M, Laitila JE, Kim J, Sam L, Sam K, Isua B, Sisol M, Wardhaugh CW, Vejmelka F, Miller SE, and Weiblen GD. 2020. Compound specific trends of chemical defences in Ficus along an elevational gradient reflect a complex selective landscape. Journal of Chemical Ecology. 46:442-454

Williams S, Williams YM, VanDerWal J, Isaac JL, Shoo LP, and Johnson CN. 2009. Ecological specialization and population size in a biodiversity hotspot: how rare species avoid extinction. Proceedings of the National Academy of Sciences 106:19737-19741.

Peer) reviewing PDF | (2019:07:39040:2:1:CHECK 1 Jul 2020) 
448

449

450

451

452

453

454

455

456

457

458

459

460

461

462

463

464

465

466

467

468

469

470

471

472

473

474

475

476

477

478

479

480

481

482

483

484

485

486

487

488

489

490

491

492

493

494
Figure 1. Location of the elevational gradient of Mt. Wilhelm in Papua New Guinea (a) and the study sites along the gradient (b).

Figure 2. Species richness (fitted with exponential function: $y=-2.4107 x^{2}+11.756 x+93.946, R^{2}=$ 0.95) of all birds recorded during point-counts from along the elevational gradient of Mt. Wilhelm (a); species richness of passerine and non-passerine birds separately (b). Total (i.e. summed) abundances of passerine (grey) and non-passerine (black) bird assemblages at respective elevational sites (c).

Figure 3. Mean elevational abundance of a passerine and non-passerine bird species $( \pm \mathrm{SE})$ (i.e. mean number of individuals of a given species at a given elevational site) occurring in the assemblages along the elevational gradient of Mt Wilhelm (fitted with loess smooth function). The patterns remain to be valid both in wet and dry season (Figure S5) and when maximal mean elevational abundances are considered (Figure S6).

Figure 4. Passerine $(a, b)$ and non-passerine $(c, d)$ birds divided into three groups based on the position of their weighted mean point of elevational distribution on Mt. Wilhelm, and their mean abundances (a, c) and geographical range sizes in $\mathrm{km}^{2}(\mathrm{~b}, \mathrm{~d})$. Kruskal-Wallis - passerines (a) $\chi^{2}=16.3$, $\mathrm{df}=2, \mathrm{~N}=161, \mathrm{P}<$ 0.001 ; (b) $\chi^{2}=67.3, \mathrm{df}=2, \mathrm{~N}=161, \mathrm{P}<0.001$; non-passerines (c) $\chi^{2}=1.2, \mathrm{df}=2, \mathrm{~N}=88, \mathrm{P}=0.549$; (d) $\chi^{2}=19.5, \mathrm{df}=2, \mathrm{~N}=88, \mathrm{P}<0.001$. Lowland group = elevational weighted mean point up to $800 \mathrm{~m}$ a.s.1., mid group $=$ elevational weighted mean point between 801 and $1600 \mathrm{~m}$ a.s.l., and montane group $=$ elevational weighted mean point above $1600 \mathrm{~m}$ a.s.l. The patterns remain valid both in wet and dry season (Figure S9) and when maximal mean elevational abundance point is considered instead of weighted mean point in analyses (Figure S10).

Figure 5. Mean elevational abundances of birds partitioned into feeding guilds (a) and total abundance of bird assemblages partitioned into feeding guilds (b). Mean abundances of birds partitioned into feeding guilds and into passerines (c) and non-passerines (d). Mean elevational abundance refers to mean number of individuals of a given species at a given elevation. Subsequently, mean abundance refers to averaged mean elevational abundances of a species across all elevations where it was present. Total abundance refers to aggregated abundances of bird assemblage at a given elevations. Ne - Nectarivores, In Insectivores, In-Ne - Insectivore-nectarivores, Fr - Frugivores, Fr-In - Frugivore-insectivores. Standard errors of the mean are not shown for the clarity of the graph. Lowland group = elevational weighted mean point up to $800 \mathrm{~m}$ a.s.1., mid group = elevational weighted mean point between 801 and $1600 \mathrm{~m}$ a.s.1., and montane group $=$ elevational weighted mean point above $1600 \mathrm{~m}$ a.s.l.

Figure 6. Mean biomass (across the re-surveys of all point-counts) of passerine and non-passerine birds (a) and birds partitioned into feeding guilds (b) of Mt. Wilhelm (total biomass in kg/12.86 ha). 
495

496

497

498

499

500

501

502

503

504

505

506

507

508

509

510

511

512

513

514 Figure 1. 


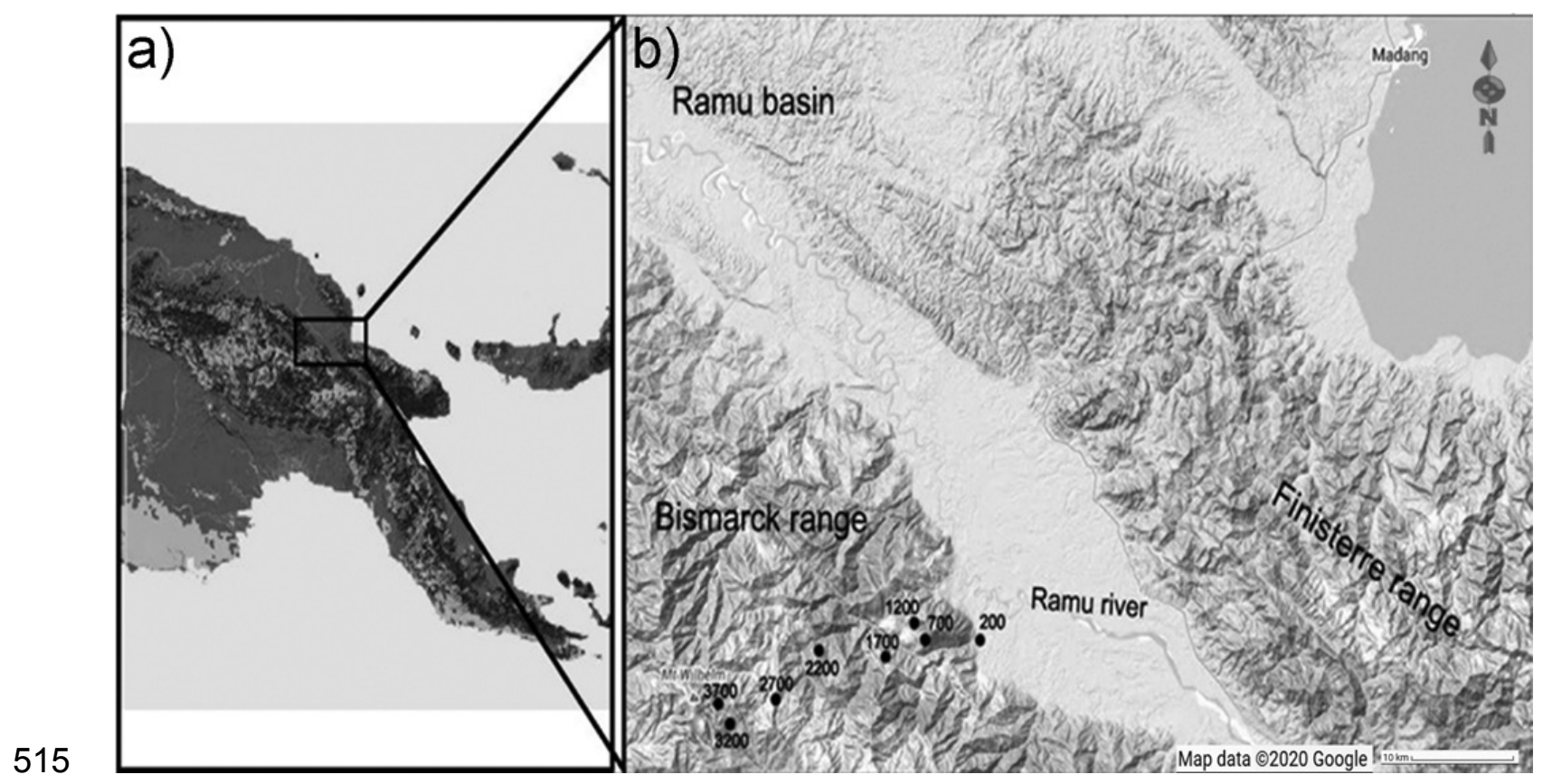

516

517

518

519

520

521

522

523

524

525

526

527

528

529

530

531 
533 Figure 2.

534 

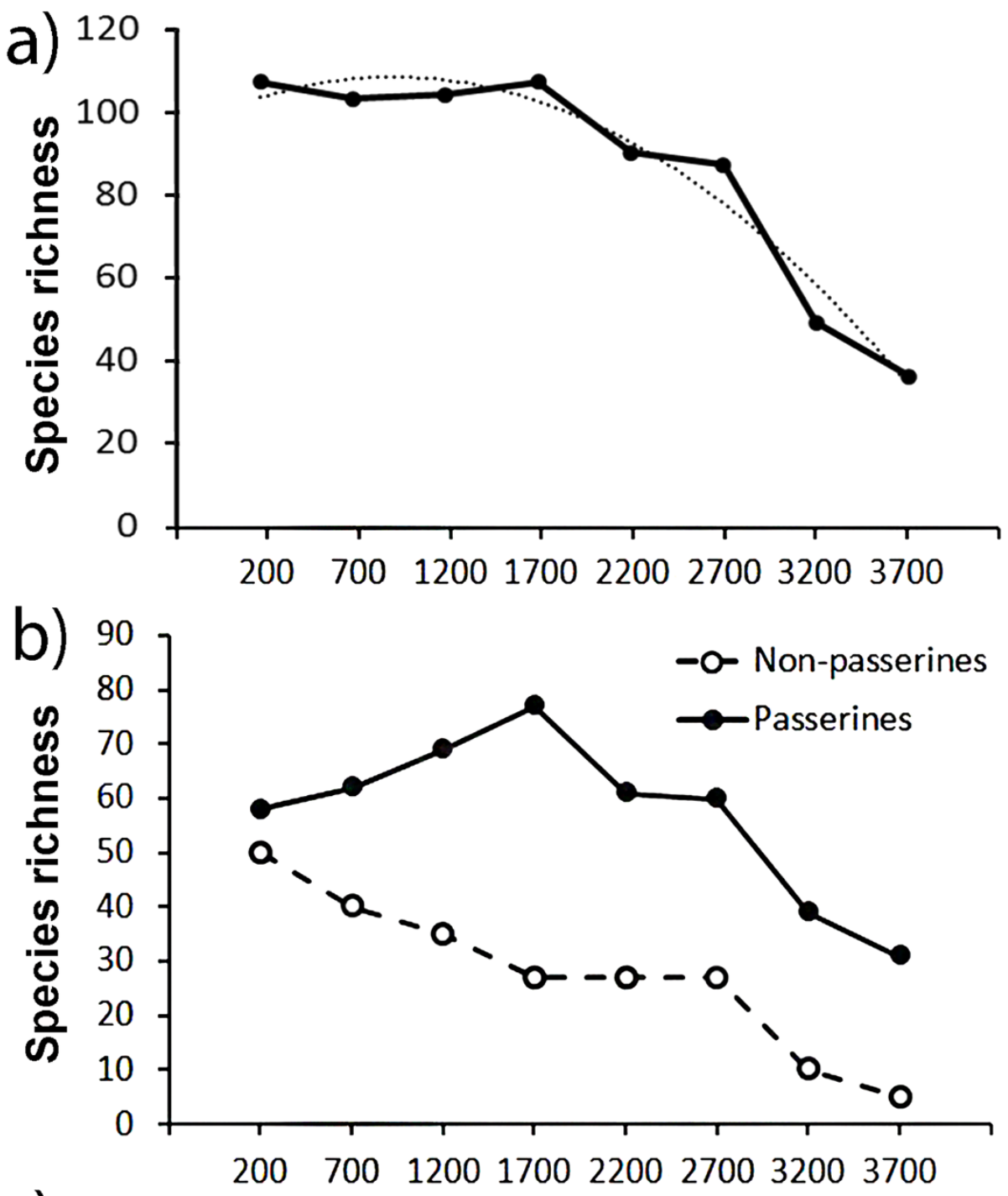

c)

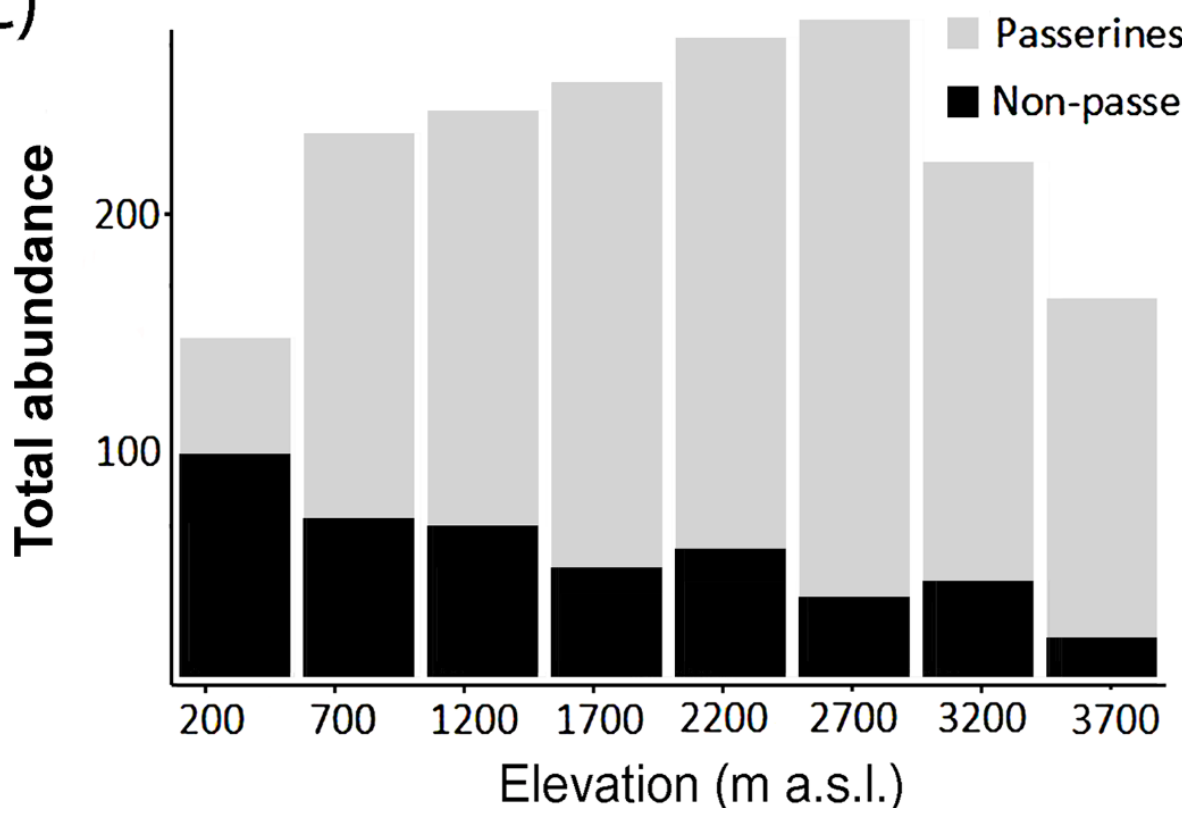


$536 \quad$ Figure 3.

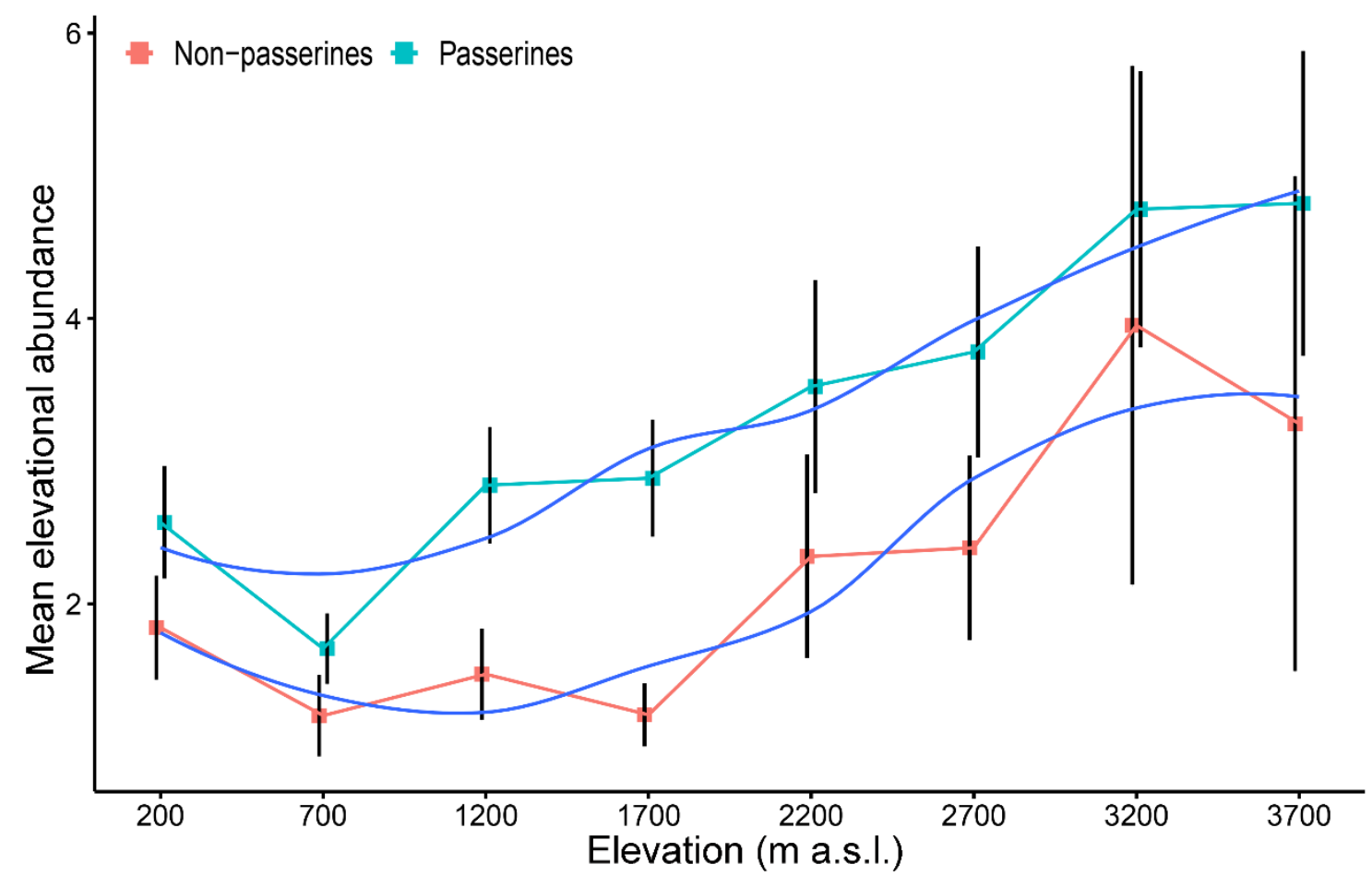

537

538

539

540

541

542

543

544

545

546

547

548

549

550 
551

552

553 Figure 4.

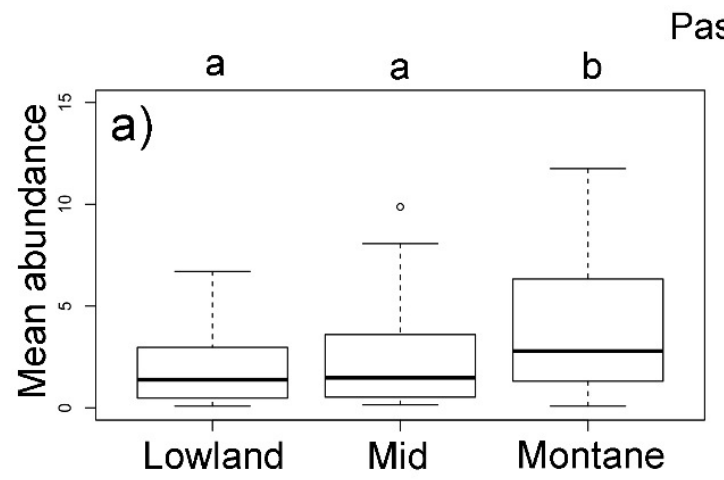

Passerines

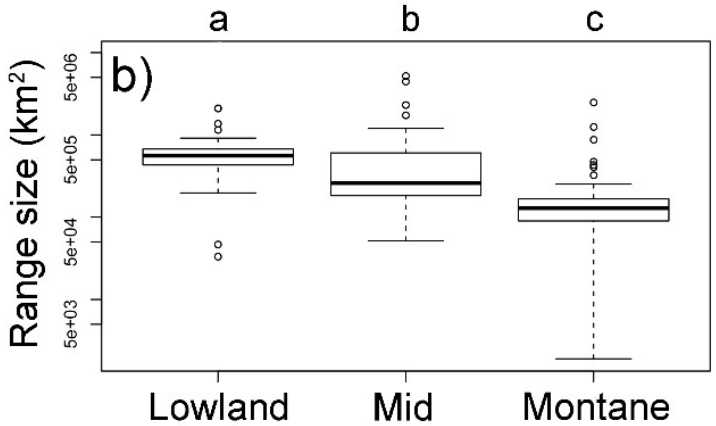

n.s.

Non-passerines
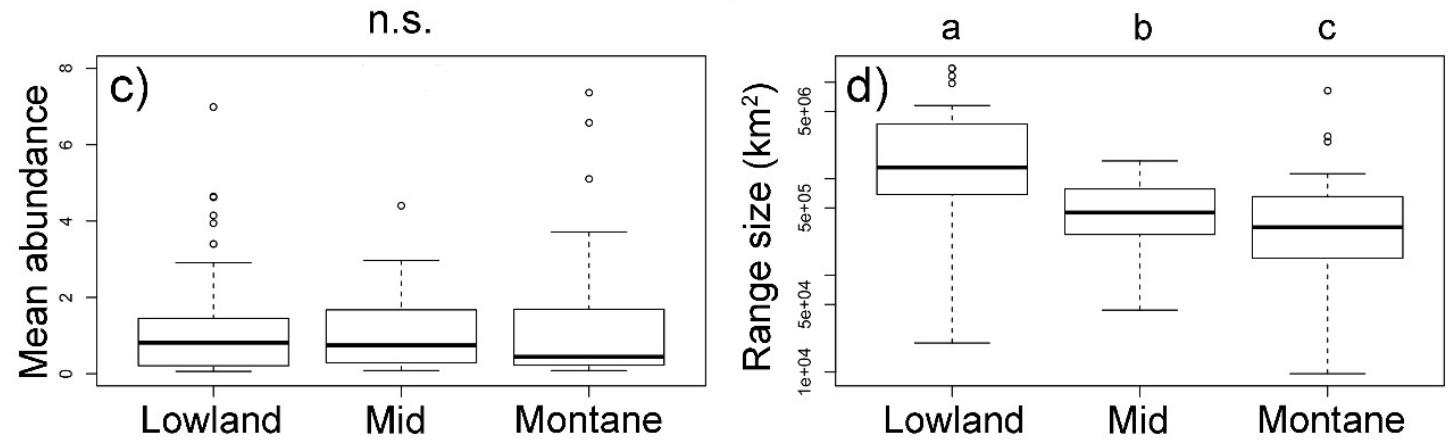

554

555

556

557

558

559

560

561

562

563

564 
565

566

567

568

569 Figure 5.
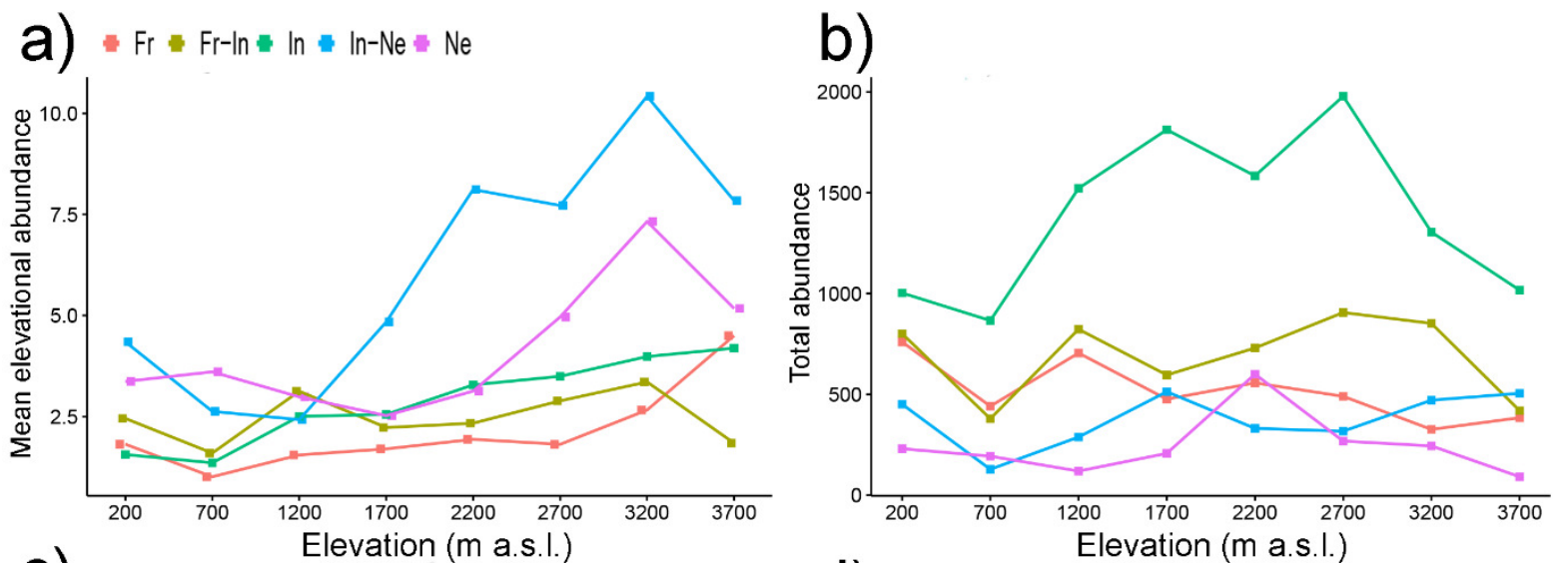

c)

d)
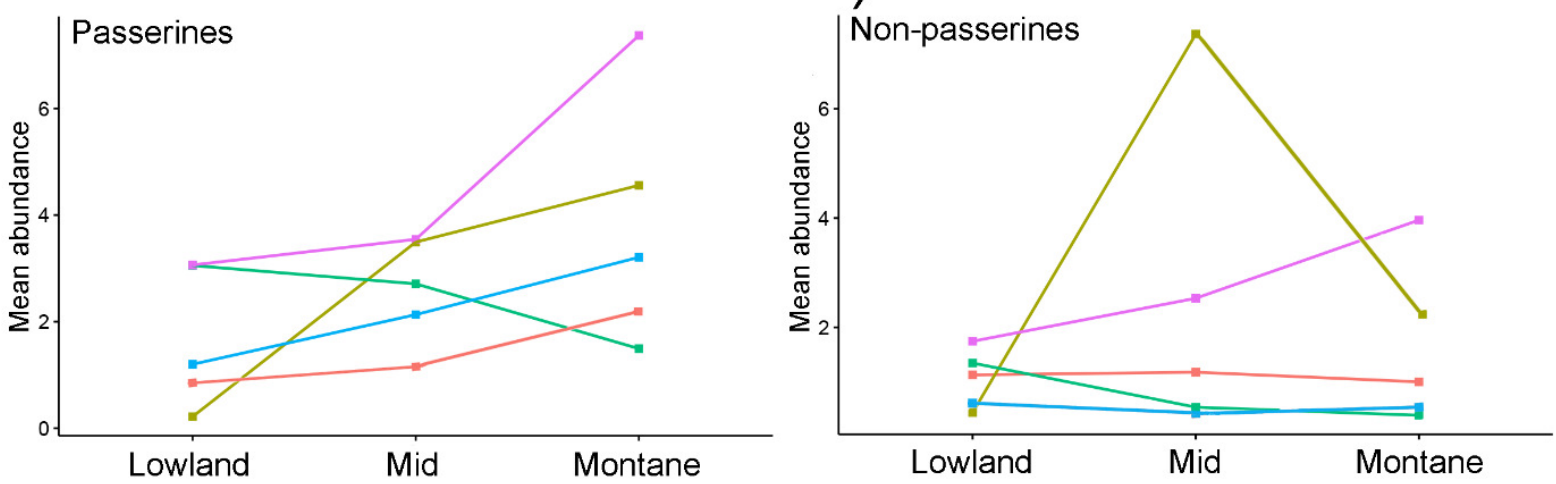

570

571

572

573

574

575

576

577

578 
579

580

581

582

583

584

585

Figure 6.
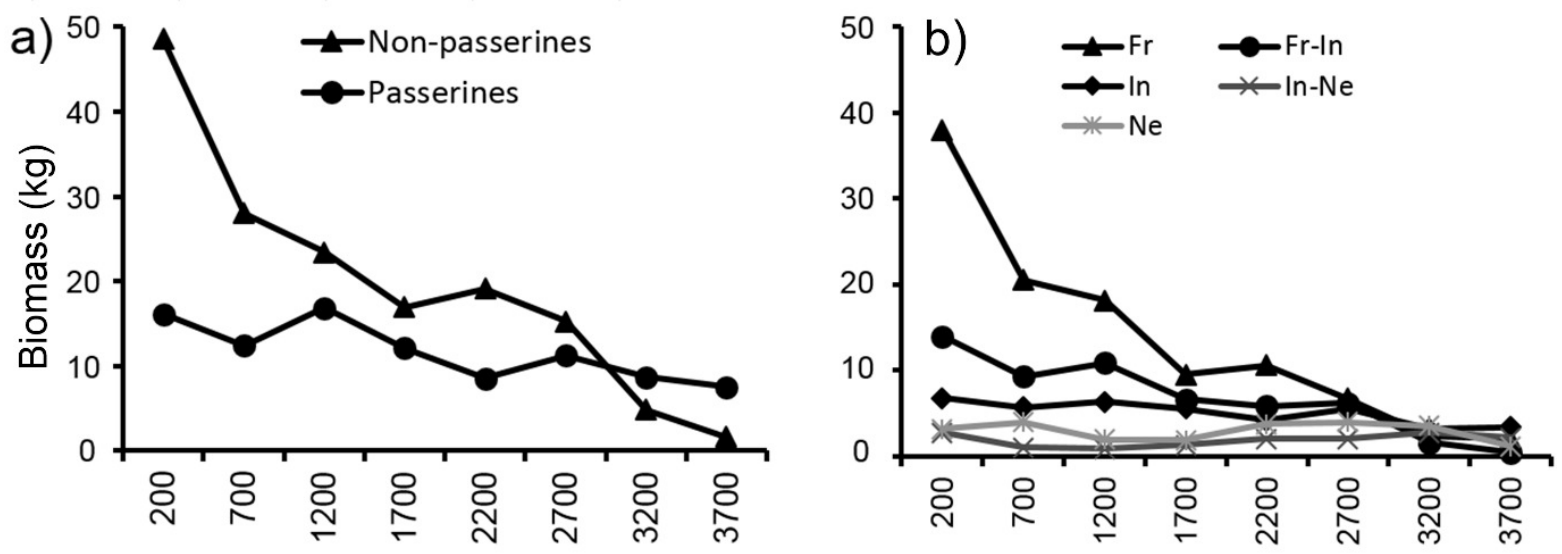

586

Elevation (m)

587

588

589

590

591

592

593

594

595

596

597

598

599

600

601

602

603

604

605

606

607 
608

609

610

611

612

613

614

615

616

617

618

619 


\section{Figure 1}

Location of the elevational gradient of Mt. Wilhelm in Papua New Guinea and the study sites along the gradient.

Location of the elevational gradient of Mt. Wilhelm in Papua New Guinea (a) and the study sites along the gradient (b). Map credit: (C) 2020 Google.

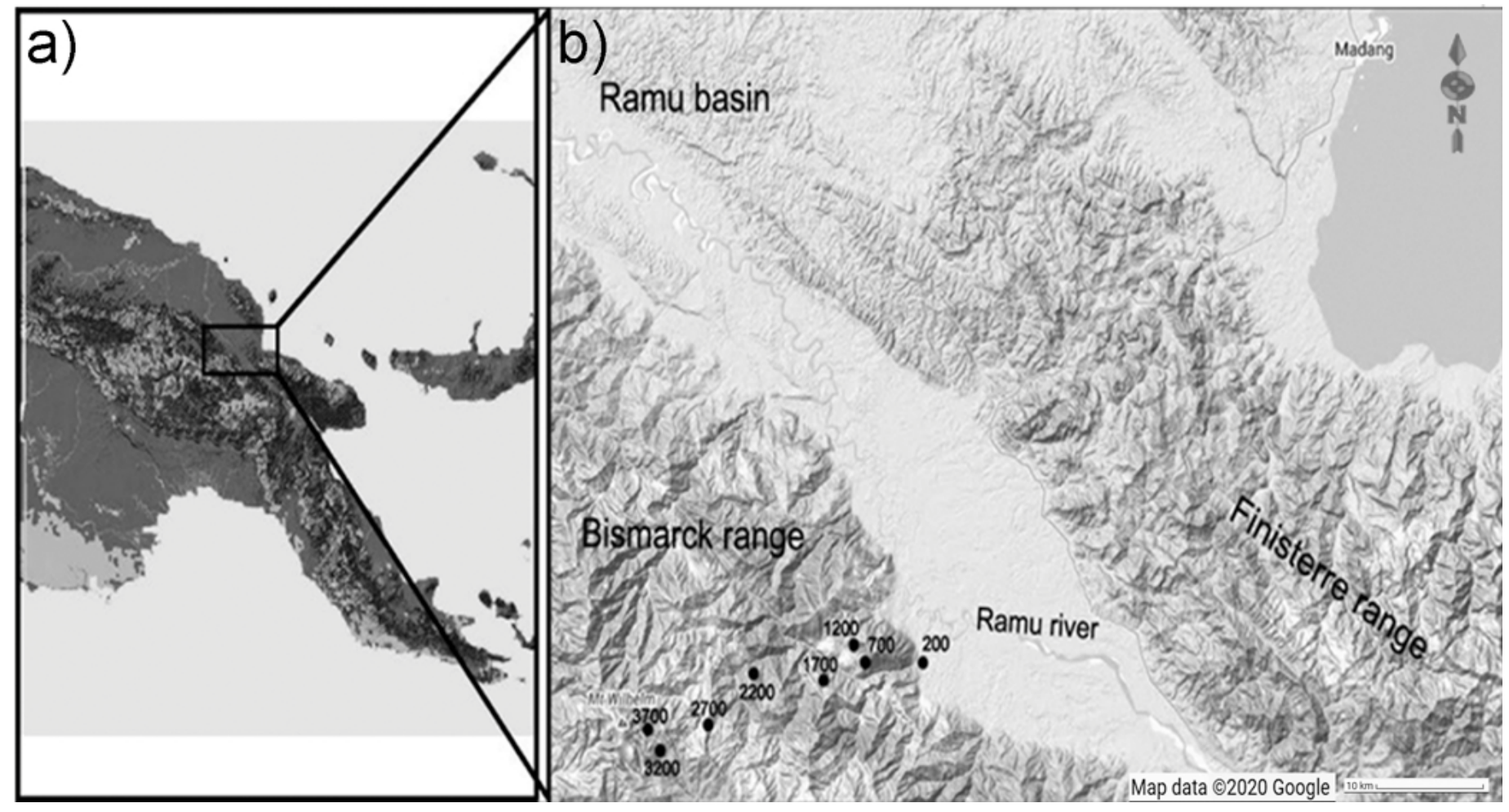




\section{Figure 2}

Patterns of species richness and total abundance of all birds along the elevational gradient of Mt. Wilhel.

Species richness (fitted with exponential function: $y=-2.4107 x^{2}+11.756 x+93.946, R^{2}=$ 0.95) of all birds recorded during point-counts from along the elevational gradient of Mt. Wilhelm (a); species richness of passerine and non-passerine birds separately (b). Total (i.e. summed) abundances of passerine (grey) and non-passerine (black) birds at respective elevational sites (c). 

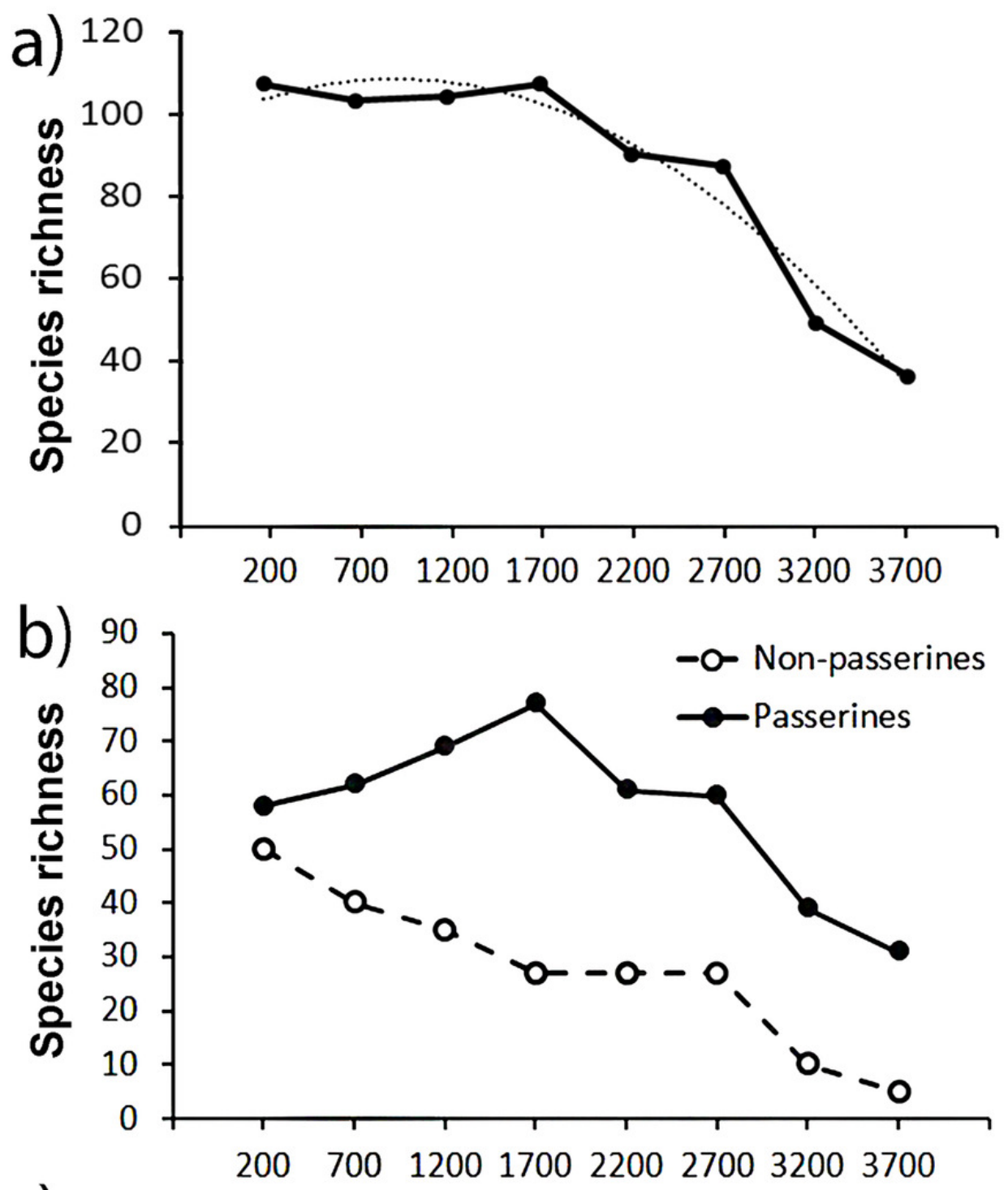

c)

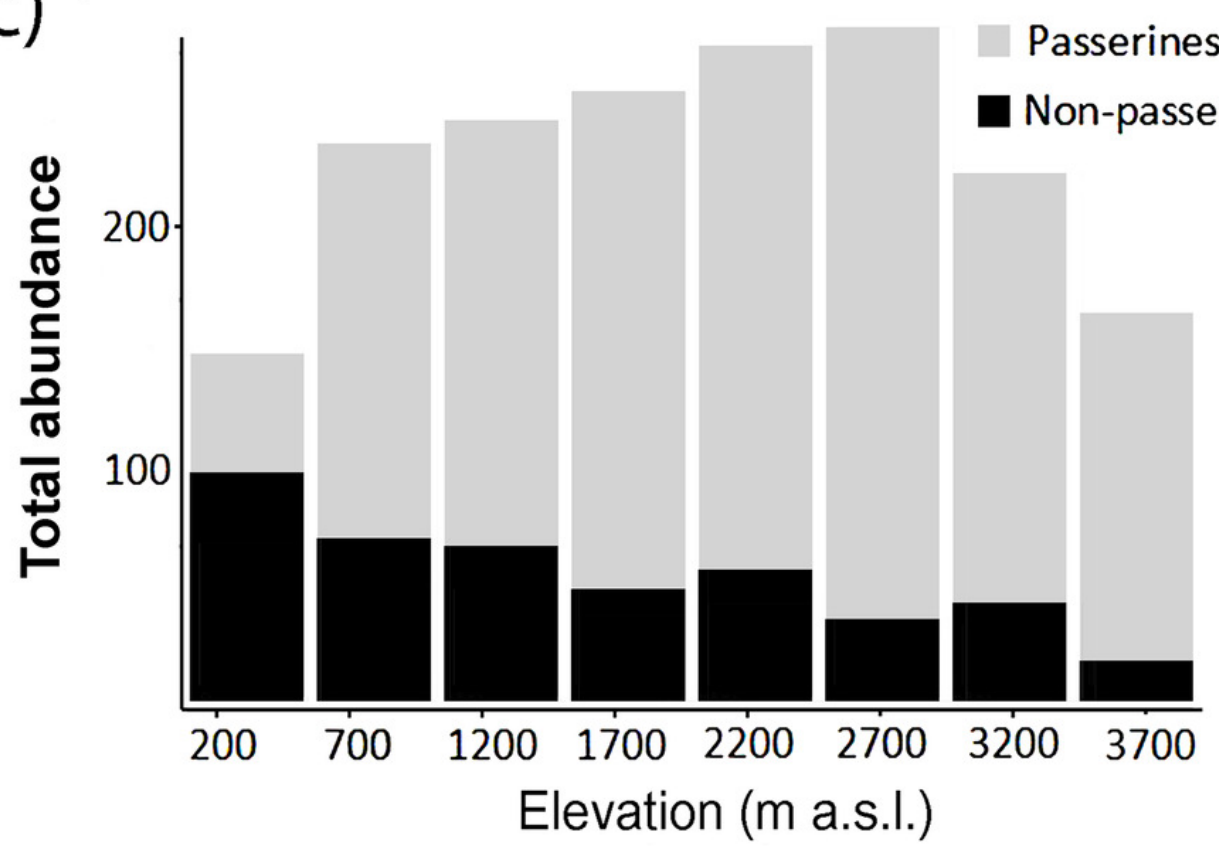


Figure 3

Mean elevational abundance of a passerine and non-passerine bird species along the elevational gradient of Mt Wilhel.

Mean elevational abundance of a passerine and non-passerine bird species ( $\pm \mathrm{SE}$ ) (i.e. mean number of individuals of a given species at a given elevation) occurring in the particular assemblage along the elevational gradient of Mt Wilhelm (fitted with loess smooth function).

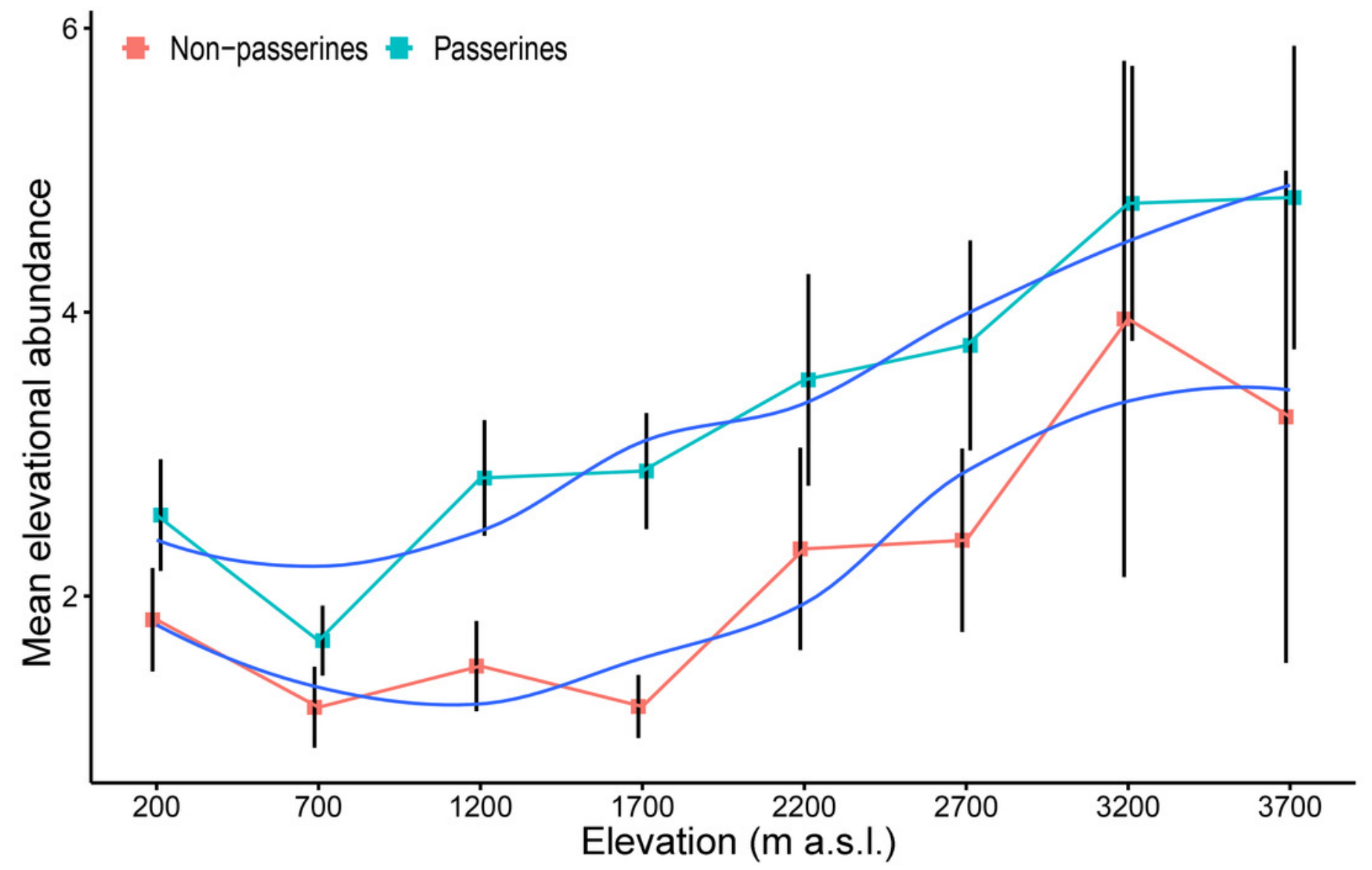




\section{Figure 4}

Passerine and non-passerine birds divided into three groups based on the position of their mean-point of elevational distribution on Mt. Wilhelm, and their mean abundances and geographical range sizes in $\mathrm{km}^{2}$

Passerine $(a, b)$ and non-passerine $(c, d)$ birds divided into three groups based on the position of their mean-point of elevational distribution on Mt. Wilhelm, and their mean abundances $(\mathrm{a}, \mathrm{c})$ and geographical range sizes in $\mathrm{km}^{2}(\mathrm{~b}, \mathrm{~d})$. Kruskal-Wallis - passerines (a) $\chi^{2}=16.3, d f=2, N=161, P<0.001 ;(b) \chi^{2}=67.3, d f=2, N=161, P<0.001 ;$ nonpasserines (c) $\chi^{2}=1.2, \mathrm{df}=2, \mathrm{~N}=88, \mathrm{P}=0.549 ;$ (d) $\chi^{2}=19.5, \mathrm{df}=2, \mathrm{~N}=88, \mathrm{P}<0.001$. Lowland group = elevational mean-point up to $800 \mathrm{~m}$ a.s.l., mid group $=$ elevational meanpoint between 801 and 1600m a.s.l., and montane group = elevational mean-point above $1600 \mathrm{~m}$ a.s.l. 


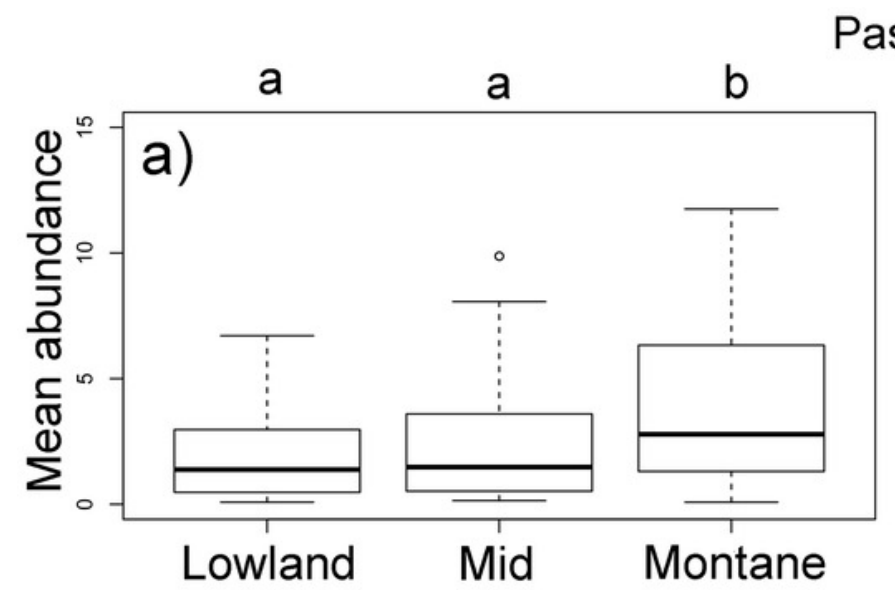

Passerines

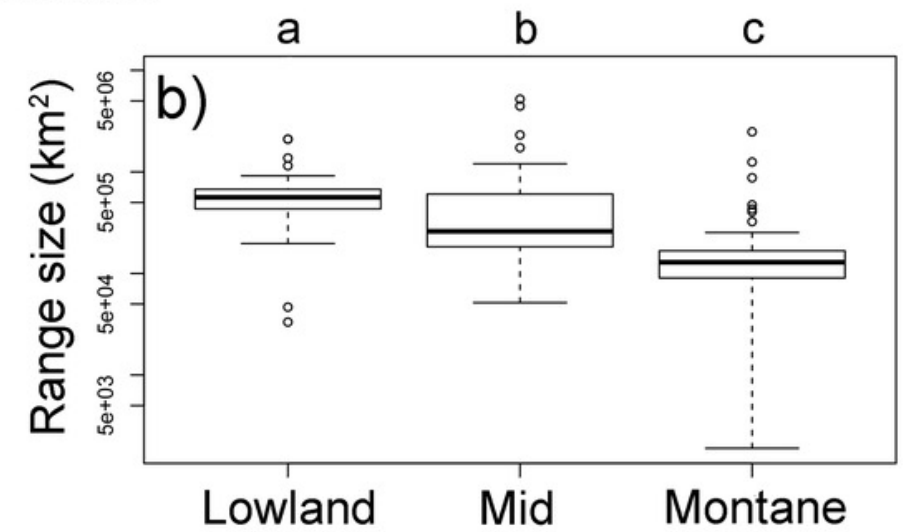

Non-passerines

n.s.

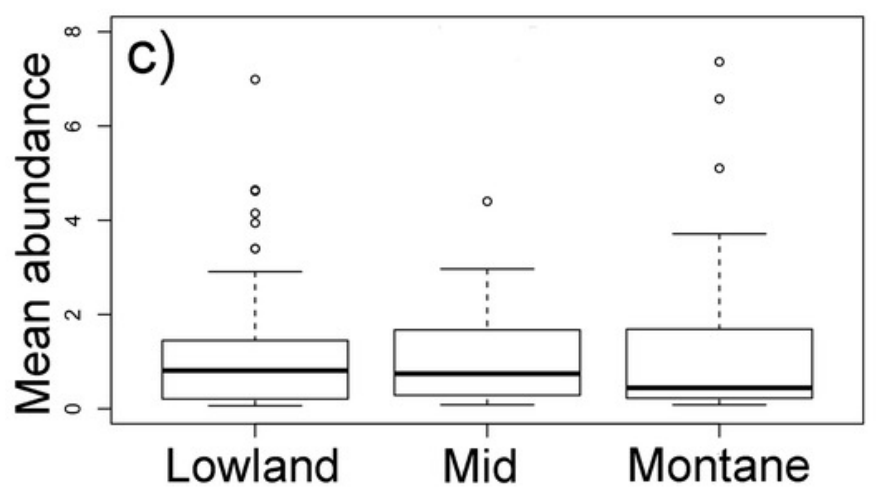

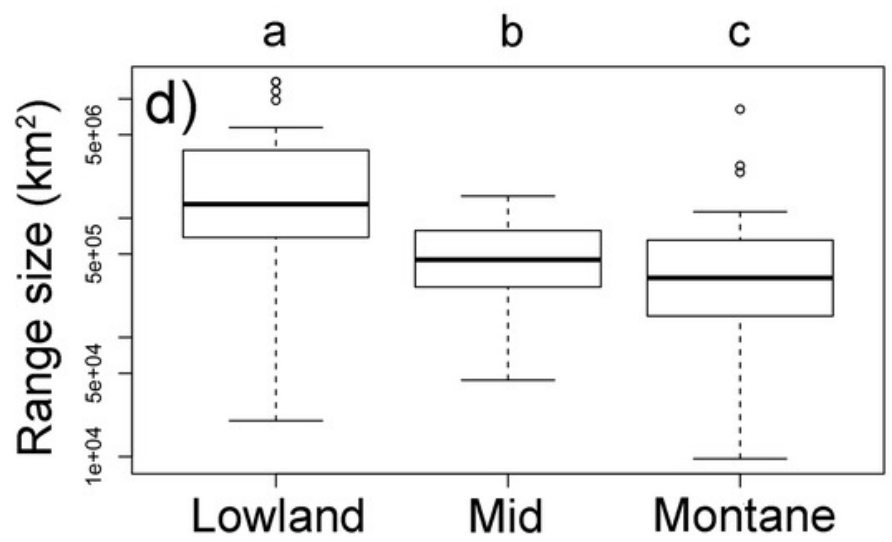




\section{Figure 5}

Mean elevational abundances of birds partitioned into feeding guilds and total abundance of bird assemblages partitioned into feeding guild.

Mean elevational abundances of birds partitioned into feeding guilds (a) and total abundance of bird assemblages partitioned into feeding guilds (b). Mean abundances of birds partitioned into feeding guilds and into passerines (c) and non-passerines (d). Mean elevational abundance refers to mean number of individuals of a given species at a given elevation. Subsequently, mean abundance refers to averaged mean elevational abundances of a species across all elevations where it was present. Total abundance refers to aggregated abundances of bird assemblage at a given elevations. Ne - Nectarivores, In - Insectivores, In$\mathrm{Ne}$ - Insectivore-nectarivores, Fr - Frugivores, Fr-In - Frugivore-insectivores. Standard errors of the mean are not shown for the clarity of the graph. Lowland group = elevational midpoint up to $800 \mathrm{~m}$ a.s.l., mid group $=$ elevational mid-point between 801 and $1600 \mathrm{~m}$ a.s.l., and montane group = elevational mid-point above $1600 \mathrm{~m}$ a.s.l. 

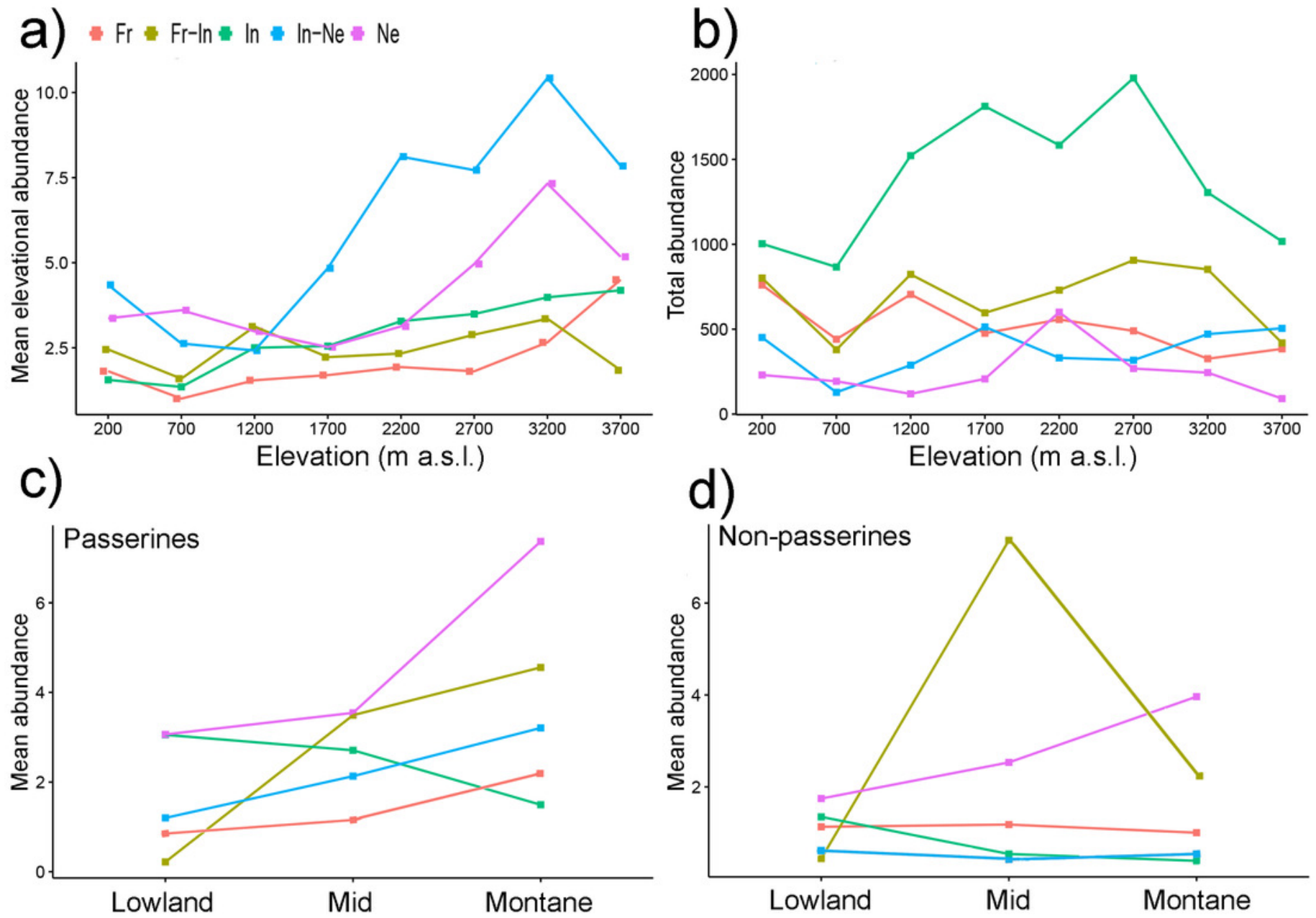
Figure 6

Mean biomass of passerine and non-passerine birds and birds partitioned into feeding guilds of Mt. Wilhelm.

Mean biomass (across the re-surveys of all point-counts) of passerine and non-passerine birds (a) and birds partitioned into feeding guilds (b) of Mt. Wilhelm (total biomass in $\mathrm{kg} / 12.86 \mathrm{ha})$.
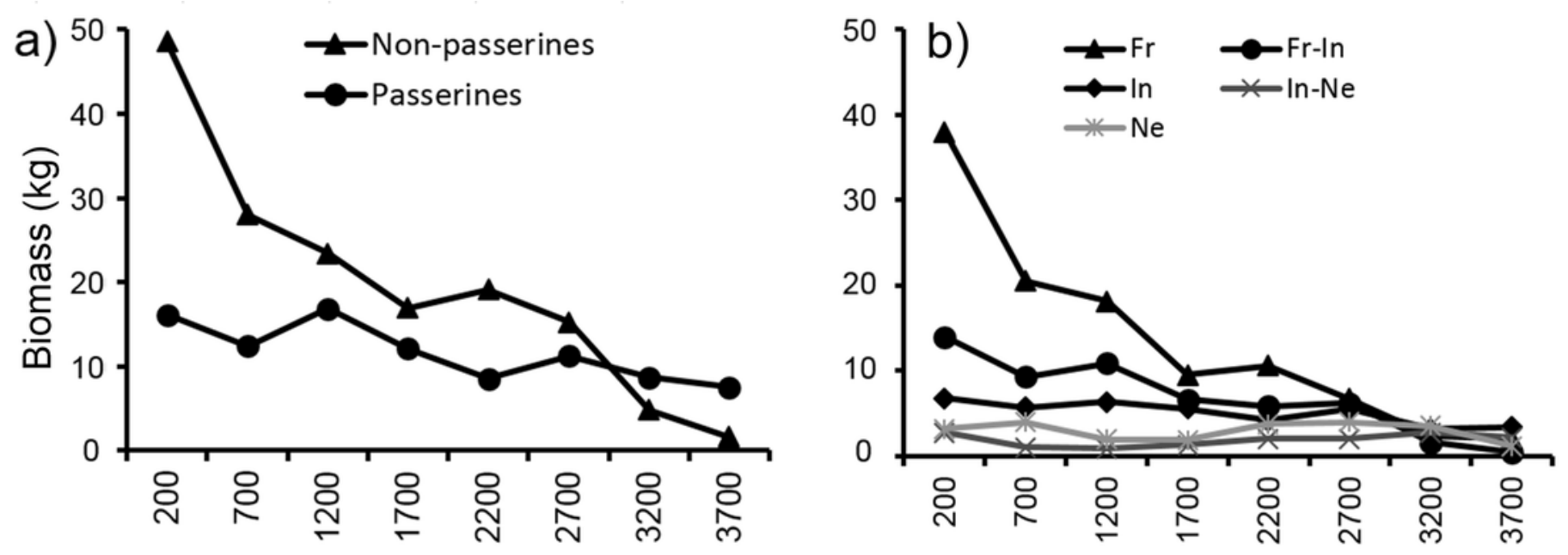

Elevation (m a.s.I.) 